\title{
A Man is Known by His Cup: Signaling Commitment via Costly Conformity ${ }^{1}$
}

\author{
Minjae Kim \\ MIT Sloan School of Management \\ minjae@mit.edu
}

\begin{abstract}
Commonly persisting are management practices that are recognized as inefficient and widely deplored, and they can often be characterized as "unpopular norms," i.e., norms to which individuals widely conform despite widespread disapproval. Why might such norms persist? Existing approaches see this issue as an information problem, where individuals misconstrue a norm as popular among others, and conform so as to feign their endorsement. But even when the unpopularity of the norm is revealed, conformity sometimes continues. My theory thus identifies when and why individuals might conform to such visibly unpopular norms by focusing on the need to credibly signal commitment to their interactants in nascent relationships. For embedded relationships to be beneficial, individuals need to discern whether their relationship partners are committed to collective interests over individual interests. In this context, conformity to a visibly unpopular norm signals that the conformist is willing to violate her own preference to meet a behavioral standard demanded by the collective (i.e., norm). Insofar as actors recognize this signaling value, visibly unpopular norms persist. Using both qualitative and experimental methods, I leverage a visibly unpopular "ideal-worker" norm - norm around excessive drinking in after-hour business gatherings in South Korea - to test this theory. A macro implication is that an unpopular norm might persist not despite visible unpopularity but precisely because of visible unpopularity.
\end{abstract}

\footnotetext{
${ }^{1}$ I am indebted to Ezra Zuckerman for his patient and generous advice on this paper. I also thank Mabel Abraham, Vanessa Conzon, Daniel DellaPosta, Jerker Denrell, Julia DiBenigno, Roberto Fernandez, Rebecca Grunberg, Jae-Kyung Ha, Oliver Hahl, Kate Kellogg, Erin Kelly, Minkyung Kim, Byungkyu Lee, David Tan, Robb Willer, and participants in the seminars at MIT Sloan, 2017 Academy of Management annual meeting, and 2017 American Sociological Association annual meeting for their feedback on the paper at various stages. My gratitude also goes to my informants who took time to talk to me about their experiences. Any errors are mine alone.
} 